\title{
Screening for Resistance to Sugarcane Brown Rust With Controlled-conditions Inoculation
}

M. C. Avellaneda and J. W. Hoy, Department of Plant Pathology and Crop Physiology, Louisiana State University Agricultural Center, Baton Rouge 70803; and M. J. Pontif, Sugar Research Station, Louisiana State University Agricultural Center, St. Gabriel 77067

\begin{abstract}
Avellaneda, M. C., Hoy, J. W., and Pontif, M. J. 2015. Screening for resistance to sugarcane brown rust with controlled-conditions inoculation. Plant Dis. 99:1633-1639.

Breeding for resistance is the primary control measure for brown rust of sugarcane. Resistance screening utilizing natural infection symptom severity ratings provides erratic results. Therefore, a method accomplishing infection and disease expression under controlled conditions was evaluated to determine whether it could provide accurate resistance ratings for seedlings and clones with known and unknown reactions. Seedlings from crosses between parents with different levels of resistance were inoculated with increasing concentrations of urediniospores. Inoculum concentration affected disease severity and the frequency of resistant progeny in crosses. Brown rust resistance is a heritable trait; however, parental reaction was not a consistent determinant of progeny distribution

across resistance rating categories. These results suggest that seedling inoculation may be misleading for the evaluation of brown rust resistance. Clone resistance reactions could not be reliably determined for susceptible clones in single inoculations. Ratings for controlled-conditions inoculation and field natural infection severity were not correlated. Multiple inoculations under controlled conditions accurately identified resistant and susceptible clones, with severe infection resulting from any single inoculation indicating susceptibility. Therefore, controlled-conditions inoculation has the potential to be useful in limited studies to characterize parents in a recurrent selection program and for basic studies of resistance to brown rust.
\end{abstract}

Brown rust of sugarcane (Saccharum interspecific hybrids), caused by Puccinia melanocephala Syd. \& P. Syd., is an important disease worldwide that can cause yield losses greater than $50 \%$ (Purdy et al. 1983; Raid and Comstock 2000). In Louisiana, total sucrose yield losses up to $22 \%$ were reported for a susceptible cultivar (Hoy and Hollier 2009). Effective brown rust management is needed for profitable sugarcane production.

Disease symptoms consist of reddish-brown lesions on the leaves, and severe infections can cause leaf necrosis and premature senescence of even young leaves. Several variables are associated with disease severity, including host resistance and pathogen genetics (Asnaghi et al. 2001; Raid and Comstock 2000; Shine et al. 2005), plant age (Comstock and Ferreira 1986; Victoria et al. 1984), weather conditions (Barrera et al. 2013; Irey 1987; Sandoval et al. 1983), and plant nutrition and soil characteristics (Anderson and Dean 1986; Anderson et al. 1990; Johnson et al. 2007). Temperature and leaf wetness are the most important environmental variables affecting brown rust development in susceptible cultivars (Barrera et al. 2013; Purdy et al. 1983; Raid and Comstock 2000; Sandoval et al. 1983). Sotomayor et al. (1983) reported the rupture of epidermis and formation of urediniospores beginning 7 days after inoculation, and Irey (1987) described a time period between 8 and 11 days to produce a new generation of spores.

Sugarcane cultivars are clonally propagated interspecific hybrids with a complex aneu-polyploid genome. Sugarcane hybrids have 100 to 120 chromosomes, with approximately $80 \%$ of the genome contributed by Saccharum officinarum $(2 n=80), 10$ to $15 \%$ by S. spontaneum $(2 n=48$ to 124$)$, and 5 to $10 \%$ from recombinations (D'Hont et al. 1996; Piperidis et al. 2001). Resistance to brown rust is a heritable trait with quantitative expression (Comstock et al. 1992; D’Hont et al. 1996; González et al. 1987; Hogarth et al. 1993; Tai

Corresponding author: J. W. Hoy; E-mail: jhoy@agcenter.lsu.edu

Accepted for publication 20 February 2015.

http://dx.doi.org/10.1094/PDIS-01-15-0078-RE

(C) 2015 The American Phytopathological Society et al. 1981). However, shifts from resistance to susceptibility have been reported repeatedly for commercial sugarcane cultivars (Dean and Purdy 1984; Hoy and Savario 2007; Raid 1989; Shine et al. 2005), and differential interactions between cultivars and pathogen populations have been demonstrated (Hoy et al. 2014; Shine et al. 2005; Srinivasan and Muthaiyan 1965). Two major resistance genes, Bru1 and Bru2, have been identified (Costet et al. 2012; Daugrois et al. 1996), and Bru1 was demonstrated to prevent infection by rust isolates from multiple geographic areas (Asnaghi et al. 2001). In Louisiana, Bru1 was detected in only one cultivar, 'L 01-299' (Parco et al. 2014), and quantitative resistance was demonstrated in ' $\mathrm{L}$ 99233' (Hoy et al. 2014).

Breeding for host plant resistance relies on ratings of the severity of symptoms resulting from natural infection in the field (Asnaghi et al. 2001; Raid and Comstock 2000; Tai et al. 1981). Although natural infection is useful in assessing resistance, it is not always reliable due to variable environmental conditions and uneven inoculum exposure.

Inoculation of plants under controlled conditions represents an alternative potential method for brown rust resistance screening. It would require virulent inoculum and favorable ambient conditions for infection and symptom development. Barrera et al. (2012) demonstrated the feasibility of sugarcane infection and disease expression under controlled conditions and established the conditions favorable for infection. A controlled-conditions inoculation method might be useful for determining and comparing brown rust resistance reactions in clonal material or seedlings.

Seedlings from crosses between Saccharum interspecific hybrid parents are populations of unique genotypes. Cross appraisal is a routine part of sugarcane breeding programs to identify desirable parents and make the most productive crosses. Seedling inoculation might provide an additional component to cross appraisal to identify superior crosses for development of brown-rust-resistant cultivars. Accurate assessment of resistance levels in clones is then needed to develop resistant cultivars and to make optimal crosses in a recurrent selection program. Therefore, the objectives of this study were to develop a method for seedling inoculation and evaluate its potential for cross appraisal of brown rust resistance and to evaluate screening under controlled conditions in comparison with natural field infection 
in a population of clones with known and unknown resistance reactions to determine its suitability for evaluating brown rust resistance.

\section{Materials and Methods}

Inoculation of seedlings to evaluate brown rust resistance. Seedlings from 11 crosses made as part of the sugarcane breeding program between parents with variable resistance levels were obtained and inoculated with $P$. melanocephala urediniospores (Table 1). Parent resistance ratings were determined within the sugarcane breeding program from a combination of plot ratings as described below and consolidated observations of the severity of natural infection over time in the field. Individual seedlings were transplanted into Styrofoam trays with 72 cells per tray (Speedling Inc., Ruskin, FL) and plants with five to six leaves were inoculated at approximately 6 weeks of age. Disease severity ratings were assigned following inoculation.

A mixed population of urediniospores of $P$. melanocephala was collected by vacuum from the abaxial surface of multiple leaves in naturally infected fields of 'Ho 95-988' and stored at $-80^{\circ} \mathrm{C}$. All collections were made during the month of May at the peak of the brown rust epidemic. Individual field collections were tested for germination rate, separated into 0.5 -g aliquots, and stored separately. Plants were inoculated with urediniospores from one collection suspended in deionized water with $0.1 \%$ Tween 20 surfactant. Spore concentration was assessed and adjusted with a hemocytometer. Spore germination rate was determined at the time of each inoculation by plating on water agar and microscopic observation.

In a preliminary experiment, seedlings from four crosses were inoculated with a urediniospore concentration of $1 \times 10^{6}$ spores $/ \mathrm{ml}$, and a high percentage of seedlings in all crosses developed severe symptoms and died within 2 weeks regardless of parent brown rust resistance levels (Avellaneda 2014). Therefore, multiple inoculum concentrations were evaluated in inoculations of seedlings in subsequent experiments to determine whether an optimal concentration could be determined. Subsets of seedlings within a cross population were inoculated with up to four urediniospore concentrations: $1 \times$ $10^{3}, 1 \times 10^{4}, 1 \times 10^{5}$, and $1 \times 10^{6}$ spores $/ \mathrm{ml}$ of inoculum.

The number of seedlings available after germination for some crosses necessitated the use of a reduced number of urediniospore concentrations for the inoculation. Approximately 72 or 144 seedlings (one or two trays) were inoculated per inoculum concentration. Subsets of cross seedling populations were randomly selected for each inoculum concentration. Seedling subsets were inoculated with different inoculum concentrations by applying inoculum with an atomizer until leaves appeared to be wet. Favorable conditions were then provided for infection and symptom development (Barrera et al. 2012). Seedlings were placed in a mist chamber overnight in the dark for 13 to $15 \mathrm{~h}$ in the first inoculation and 10 to $12 \mathrm{~h}$ in the second inoculation. Ultrasonic cool mist generators (Kaz Incorporated, Hudson, NY) were used to maintain leaf wetness. Temperature

Table 1. Eleven sugarcane crosses inoculated with Puccinia melanocephala

\begin{tabular}{llll}
\hline Cross & Maternal parent & Paternal parent & Parental reactions $^{\mathbf{z}}$ \\
\hline XL 07-065 & LCP 81-10 & HoCP 96-540 & MS $\times$ HS \\
XL 07-082 & HoCP 96-540 & L 99-226 & HS $\times$ HS \\
XL 09-003 & LCP 81-10 & L 99-233 & MS $\times$ R \\
XL 09-100 & HoCP 96-540 & L 99-233 & HS $\times$ R \\
XL 11-062 & HoCP 91-552 & HoCP 04-838 & R $\times$ R \\
XL 11-087 & HoCP 04-838 & LCP 86-454 & R $\times$ HS \\
XL 11-144 & L 97-128 & L 99-233 & MS $\times$ R \\
XL 11-218 & LCP 85-384 & L 99-226 & HS $\times$ HS \\
XL 11-256 & HoCP 85-845 & L 01-299 & MS $\times$ R \\
XL 11-458 & Ho 95-988 & L 09-125 & HS $\times$ HS \\
XL 11-580 & Ho 95-988 & HoCP 96-540 & HS $\times$ HS \\
\hline
\end{tabular}

${ }^{\mathrm{z}}$ Crosses were made between parents rated in the breeding program as resistant (R), moderately susceptible (MS), or highly susceptible (HS) to brown rust. Ratings were based on repeated field observations of natural infection severity. was monitored with a thermocouple sensor (Spectrum Technologies, Plainfield, IL), and a temperature range of $23 \pm 1{ }^{\circ} \mathrm{C}$ favorable for spore germination and infection was maintained. After the infection period, the seedling trays were relocated to shelves under artificial lighting (two 40-W fluorescent bulbs, 2,200 lumens each), with a temperature range of $22 \pm 1{ }^{\circ} \mathrm{C}$ and a photoperiod of $12 \mathrm{~h}$ /day.

Individual seedlings were rated for brown rust symptom severity using a 1-to-9 modified scale, where $1=$ chlorotic flecks, less than 5 lesions per leaf; $3=5$ to 30 lesions per leaf; $5=$ more than 30 lesions per leaf; $7=$ some leaves with densely concentrated lesions; and $9=$ high lesion density on most leaves. A rust rating of 1 was considered resistant, 3 was moderately resistant, 5 was moderately susceptible, 7 was susceptible, and 9 was highly susceptible. The five-interval rating scale was expanded to a 1-to-9 scale to match the scale used by the breeding program and used in the clonal evaluation portion of the study. Ratings were assigned 2 weeks after inoculation.

Each cross was unique; therefore, all 11 crosses were analyzed together. A Proc GLM analysis was conducted after determining the normality of the data by Shapiro-Wilk test using SAS (version 9.4; SAS Institute Inc. Cary, NC) to determine the effects of cross, inoculum concentration, and possible interaction. The effect of inoculum concentration on the frequencies of seedlings with the different ratings was determined within each cross with a $\chi^{2}$ test of independence.

Inoculation of sugarcane clones for brown rust resistance evaluation. Plants of 21 sugarcane clones were produced vegetatively from single-node cuttings in the greenhouse and used in three repeated experiments to evaluate the ability of inoculation under controlled conditions to determine and compare brown rust resistance ratings in clones with variable levels of resistance. The study included commercial cultivars with known resistance reactions and clones with unknown reactions. Four susceptible cultivars ('LCP 85-384', Ho 95-988, 'HoCP 96-540', and 'L 99-226') and two resistant cultivars (L 99-233 and L 01-299) were included. The plants were grown in 3.8-liter pots in a 1:1 mixture of silt loam soil and sand and had approximately four fully emerged leaves at the time of inoculation.

Plants were inoculated with a concentration of $1 \times 10^{6}$ urediniospores $/ \mathrm{ml}$ in deionized water with $0.1 \%$ Tween 20 surfactant. The first inoculation used spores from a single field, and the germination rate on water agar was $31 \%$. The second and third inoculations were done with spores from a second field, and the germination rates were 38 and $29 \%$, respectively. Inoculum was applied to both sides of the two youngest fully emerged leaves with mostly horizontal orientation for each plant with a brush, until a film of moisture was visible (Barrera et al. 2012). Three plants of each cultivar were inoculated and placed in an indoor mist chamber of plastic sheeting, misted with distilled water, and kept in the mist chamber for 13 to $15 \mathrm{~h}$ at $23 \pm 1^{\circ} \mathrm{C}$, as described previously. After the infection period, the plants were relocated to shelves under artificial lighting at $22 \pm 1{ }^{\circ} \mathrm{C}$.

After 2 weeks, inoculated leaves were cut and scanned, and the percentage of leaf area occupied by brown rust lesions was determined by image analysis using Assess 2.0 Image Analysis Software (American Phytopathological Society, St. Paul, MN). Resistance ratings were assigned to clones using a 1-to- 9 scale, in which 1 to 3 were resistant categories, 4 to 6 were moderately susceptible categories, and 7 to 9 were highly susceptible categories. Disease severity for the commercial cultivars known to be highly susceptible to brown rust provided the basis for assignment of severity ratings. The leaf infection percentages for three susceptible cultivars (LCP 85-384, Ho 95-988, and HoCP 96-540) were averaged, and that value was assigned a susceptible rating of 7 . That percentage was then divided by seven to determine the percent interval between ratings, and ratings were assigned to all clones.

After testing the normality of the data by Shapiro-Wilk, statistical analysis of the percent leaf area occupied by lesions data were performed using PROC GLM from SAS, version 9.4. Mean separations were determined by Tukey's test.

Natural infection severity ratings of clones in field nurseries. Twenty-eight clones planted in breeding program nurseries at the 
Louisiana State University Agricultural Center Sugar Research Station at St. Gabriel were rated visually for brown rust severity under natural infection conditions. The ratings were recorded during the spring month of May 2011, when P. melanocephala inoculum pressure was high and severe brown rust symptoms were evident. Ratings were independently assigned by three people based on visual observation of symptom severity on older and younger leaves of five plants in single-row field plots in three different nurseries using a 1-to-9 rating scale, where $1=$ little or no symptoms; 2 = few to moderate lesions on older leaves; 3 = moderate lesions on older leaves, with a few lesions on young leaves; $4=$ moderate lesions on older leaves, with necrosis and moderate lesions on some young leaves; $5=$ moderate to extensive lesions and necrosis on older leaves and moderate lesions on young leaves; $6=$ extensive lesions and necrosis on older leaves and moderate lesions with tip necrosis on young leaves; 7 = extensive necrosis on older leaves and moderate to extensive lesions with tip necrosis on young leaves; $8=$ extensive necrosis on older leaves and moderate to extensive lesions with tip necrosis on youngest leaves; and $9=$ total senescence of older leaves and moderate to extensive lesions on young leaves, with extensive necrosis. Ratings 1 to 3 were considered resistant, 4 to 6 were considered moderately susceptible, and 7 to 9 were considered highly susceptible. A mean rating was determined from the three ratings for each clone within a nursery, and an overall mean was determined for the three nurseries combined. Brown rust severity ratings for 20 clones included in all three field nurseries were compared by Spearman's Rank correlation analysis using SAS, version 9.4.

Comparison between severity ratings from controlledconditions inoculations and natural field infection ratings. Brown rust severity ratings for 16 clones in all three controlled-conditions inoculations and natural field infection in the first and third field nurseries (that included resistant L 99-233 and L 01-299) were compared by Spearman's rank correlation analysis using SAS, version 9.4.

\section{Results}

Seedling inoculations. The frequency distribution of seedlings across resistance ratings was affected by cross $(F=161.17, P<$ $0.0001)$, inoculum concentration $(F=639.71, P<0.0001)$, and the cross-inoculum interaction $(F=33.17, P<0.0001)$. Therefore, the results are presented separately for each cross.

Cross XL 07-065 between moderately susceptible (MS) female and highly susceptible (HS) male parents was inoculated with three different urediniospores concentrations. Most seedlings (90\%) received a resistant $(\mathrm{R})$ rating when inoculated with a concentration of $1 \times 10^{3}$ spores $/ \mathrm{ml}$ (Table 2 ). When seedlings were inoculated with a concentration of $1 \times 10^{4}$ spores $/ \mathrm{ml}, 60 \%$ were $\mathrm{R}$. In contrast, inoculation with a concentration of $1 \times 10^{5}$ spores $/ \mathrm{ml}$ resulted in $80 \%$ of the seedlings being rated as susceptible (S), although no seedlings received a rating of 9 . A $\chi^{2}$ analysis indicated that the results of this cross were influenced by inoculum concentration $\left(\chi^{2}=102.4, P<\right.$ $0.0001)$.

Cross XL 07-082 between two HS parents was inoculated with only two inoculum concentrations. At the lower $1 \times 10^{4}$ inoculum concentration, $100 \%$ of seedlings were rated as $\mathrm{R}$ (Table 2). However, increasing the inoculum concentration to $1 \times 10^{5}$ spores $/ \mathrm{ml}$ resulted in $90 \% \mathrm{~S}$ seedlings. Inoculum concentration affected the frequency distribution of seedlings across severity ratings $\left(\chi^{2}=51.9\right.$, $P<0.0001)$.

Cross XL 09-003 between MS female and R male parents showed a frequency distribution of seedlings across $\mathrm{R}$ and $\mathrm{S}$ severity ratings for two inoculum concentrations. Inoculation with concentrations of $1 \times 10^{4}$ and $1 \times 10^{5}$ spores $/ \mathrm{ml}$ resulted in frequencies of 93 and $97 \% \mathrm{~S}$ seedlings, respectively (Table 2). Inoculum concentration did not affect the frequency distribution of the seedlings across severity ratings $\left(\chi^{2}=16.8, P<0.0001\right)$.

Cross XL 09-100 between HS female and R male parents exhibited variable frequency distributions of seedlings across severity ratings for four inoculum concentrations, with increased frequencies and percentages in $\mathrm{S}$ ratings at higher concentrations. For seedlings inoculated with a concentration of $1 \times 10^{6}$ spores $/ \mathrm{ml}$,
$98 \%$ were rated as $\mathrm{S}$, with $40 \%$ receiving a rating of 9 (Table 2). In contrast, 72 and $83 \%$ of seedlings were rated as R for the $1 \times$ $10^{3}$ and $1 \times 10^{4}$ spores $/ \mathrm{ml}$ inoculum concentrations, respectively. The reactions of seedlings inoculated with $1 \times 10^{5}$ spores $/ \mathrm{ml}$ ranged across $\mathrm{R}$ and $\mathrm{S}$ ratings, with $83 \%$ rated $\mathrm{S}$. Inoculum concentration affected the frequency distribution of seedlings across severity ratings $\left(\chi^{2}=436.1, P<0.0001\right)$.

Seedlings from XL 11-062, the only cross between two R parents, exhibited high frequencies of seedlings in the $\mathrm{R}$ severity ratings at two inoculum concentrations: $100 \%$ at $1 \times 10^{4}$ and $83 \%$ at $1 \times$ $10^{5}$ spores $/ \mathrm{ml}$ (Table 2). However, $\chi^{2}$ analysis indicated that the frequency distribution of seedlings was affected by inoculum concentration $\left(\chi^{2}=64.1, P<0.0001\right)$.

Cross XL 11-087 between R female and HS male parents was inoculated with all four inoculum concentrations (Table 2). With an inoculum concentration of $1 \times 10^{3}$ spores $/ \mathrm{ml}, 76 \%$ of the seedlings were R. As the inoculum concentration increased, the distribution shifted to more seedlings with $\mathrm{S}$ ratings, with 42 and $59 \%$ rated as $\mathrm{S}$ with the $1 \times 10^{5}$ and $1 \times 10^{6}$ spores/ml concentrations, respectively (Table 2). The frequency distribution was affected by inoculum concentration $\left(\chi^{2}=47.2, P<0.0001\right)$

Seedlings from two crosses between MS female and $\mathrm{R}$ male parents, XL 11-144 and XL 11-256, showed frequency distributions of seedlings with mostly R severity ratings for two inoculum concentrations (Table 2). For XL 11-144, 100\% of the seedlings were rated as 1 or 3 for both inoculum concentrations, while 100 and $93 \%$ of XL 11-256 seedlings were rated as 1 or 3 with $1 \times 10^{4}$ and $1 \times$ $10^{5}$ spores $/ \mathrm{ml}$, respectively. The seedling frequency distributions were affected by inoculum concentration for both crosses $\left(\chi^{2}=\right.$

Table 2. Distribution of seedlings across disease severity ratings at 2 weeks after inoculation for 11 sugarcane crosses inoculated with four urediniospore concentrations

\begin{tabular}{|c|c|c|c|c|c|c|}
\hline \multirow[b]{2}{*}{ Cross } & \multirow[b]{2}{*}{ Urediniospore concentration } & \multicolumn{5}{|c|}{$\begin{array}{l}\text { Percentage of seedlings in } \\
\text { five severity ratings }\end{array}$} \\
\hline & & 1 & 3 & 5 & 7 & 9 \\
\hline \multirow[t]{3}{*}{ XL 07-065 } & $1.0 \mathrm{E}+03$ & 69 & 21 & 10 & 0 & $\overline{0}$ \\
\hline & $1.0 \mathrm{E}+04$ & 12 & 48 & 40 & 0 & 0 \\
\hline & $1.0 \mathrm{E}+05$ & 6 & 13 & 48 & 32 & 0 \\
\hline \multirow[t]{2}{*}{ XL 07-082 } & $1.0 \mathrm{E}+04$ & 85 & 15 & 0 & 0 & 0 \\
\hline & $1.0 \mathrm{E}+05$ & 5 & 5 & 33 & 57 & 0 \\
\hline \multirow[t]{2}{*}{ XL 09-003 } & $1.0 \mathrm{E}+04$ & 0 & 7 & 89 & 4 & 0 \\
\hline & $1.0 \mathrm{E}+05$ & 0 & 3 & 44 & 53 & 0 \\
\hline \multirow[t]{4}{*}{ XL 09-100 } & $1.0 \mathrm{E}+03$ & 61 & 11 & 28 & 0 & 0 \\
\hline & $1.0 \mathrm{E}+04$ & 47 & 36 & 17 & 0 & 0 \\
\hline & $1.0 \mathrm{E}+05$ & 3 & 14 & 69 & 14 & 0 \\
\hline & $1.0 \mathrm{E}+06$ & 0 & 2 & 7 & 51 & 40 \\
\hline \multirow[t]{2}{*}{ XL 11-062 } & $1.0 \mathrm{E}+04$ & 84 & 16 & 0 & 0 & 0 \\
\hline & $1.0 \mathrm{E}+05$ & 34 & 49 & 17 & 0 & 0 \\
\hline \multirow[t]{4}{*}{ XL 11-087 } & $1.0 \mathrm{E}+03$ & 42 & 34 & 24 & 0 & 0 \\
\hline & $1.0 \mathrm{E}+04$ & 32 & 45 & 23 & 0 & 0 \\
\hline & $1.0 \mathrm{E}+05$ & 11 & 47 & 33 & 4 & 5 \\
\hline & $1.0 \mathrm{E}+06$ & 4 & 37 & 53 & 6 & 0 \\
\hline \multirow[t]{2}{*}{ XL 11-144 } & $1.0 \mathrm{E}+04$ & 90 & 10 & 0 & 0 & 0 \\
\hline & $1.0 \mathrm{E}+05$ & 76 & 24 & 0 & 0 & 0 \\
\hline \multirow[t]{2}{*}{ XL 11-218 } & $1.0 \mathrm{E}+04$ & 77 & 23 & 0 & 0 & 0 \\
\hline & $1.0 \mathrm{E}+05$ & 47 & 37 & 16 & 0 & 0 \\
\hline \multirow[t]{2}{*}{ XL 11-256 } & $1.0 \mathrm{E}+04$ & 73 & 27 & 0 & 0 & 0 \\
\hline & $1.0 \mathrm{E}+05$ & 37 & 56 & 7 & 0 & 0 \\
\hline \multirow[t]{2}{*}{ XL 11-458 } & $1.0 \mathrm{E}+04$ & 57 & 40 & 3 & 0 & 0 \\
\hline & $1.0 \mathrm{E}+05$ & 3 & 30 & 63 & 4 & 0 \\
\hline \multirow[t]{2}{*}{ XL 11-580 } & $1.0 \mathrm{E}+04$ & 77 & 23 & 0 & 0 & 0 \\
\hline & $1.0 \mathrm{E}+05$ & 7 & 51 & 41 & 1 & 0 \\
\hline
\end{tabular}

${ }^{\mathrm{z}}$ Disease severity ratings were assigned on a modified 1-to-9 scale, in which $1=$ highly resistant, $3=$ moderately resistant, $5=$ moderately susceptible, $7=$ susceptible, and $9=$ highly susceptible. Values in columns are the percentages of seedlings assigned with each severity rating. 
5.0, $P=0.0251$ for XL $11-144$ and $\chi^{2}=21.1, P<0.0001$ for XL 11-256).

Three crosses between HS parents-XL 11-218, XL 11-458, and XL 11-580 - showed variable distributions of seedlings across severity ratings with two inoculum concentrations: $1 \times 10^{4}$ and $1 \times$ $10^{5}$ spores $/ \mathrm{ml}$. For cross XL 11-218, all seedlings were rated as R with $1 \times 10^{4}$ spores $/ \mathrm{ml}$, and only $16 \%$ were rated as $\mathrm{S}$ with $1 \times 10^{5}$ spores/ml (Table 2). Seedlings from crosses XL 458 and XL 11580 exhibited a stronger contrast between inoculum concentrations (Table 2). XL 11-458 had 3\% S seedlings with $1 \times 10^{4}$ spores $/ \mathrm{ml}$ compared with $67 \%$ with $1 \times 10^{5}$ spores $/ \mathrm{ml}$, while XL 11-580 had no and $42 \% \mathrm{~S}$ seedlings, respectively. The distribution of seedlings across ratings was affected by inoculum concentration for all three crosses $\left(\chi^{2}=38.1, P<0.0001\right.$ for XL 11-218; $\chi^{2}=150.2, P<$ 0.0001 for XL 11-458; and $\chi^{2}=112.0, P<0.0001$ for XL 11-580).

To evaluate the possible relationship between the frequency of $\mathrm{R}$ progeny with parental resistance reactions, the percentages of seedlings with R severity ratings of 1 and 3 were combined for each cross and compared for inoculum concentrations of $1 \times 10^{4}$ and $1 \times 10^{5}$ spores $/ \mathrm{ml}$ (the inoculum concentrations that produced the widest distribution of seedlings across ratings) (Table 3). Inoculation with the lower spore concentration resulted in progeny frequency distributions skewed toward the $\mathrm{R}$ ratings, with an overall cross average of $84 \%$ and range of 7 to $100 \%$. In contrast, inoculation with $1 \times 10^{5}$ spores $/ \mathrm{ml}$ resulted in an overall average of $51 \%$ and range of 3 to $100 \%$. The magnitude of the shift varied among cross types. Seven crosses involving an HS parent had an average change from one inoculum concentration to the other of $48 \%$, with a range of 15 to $90 \%$, whereas six crosses involving an $\mathrm{R}$ parent had an average shift of $17 \%$, with a range of 0 to $66 \%$. Comparing the total frequencies of seedlings with $\mathrm{R}$ ratings using the more severe inoculation $(1 \times$ $10^{5}$ spores $/ \mathrm{ml}$ ), the frequency of seedlings rated as $\mathrm{R}$ in six crosses with at least one $\mathrm{R}$ parent averaged 59\% and ranged from 3 to $100 \%$. In comparison, the frequency of seedlings rated as $\mathrm{R}$ in seven crosses with at least one HS parent averaged $40 \%$ and ranged from 10 to $84 \%$.

Table 3. Percentages of resistant seedlings from 11 crosses with different parental resistance reactions to brown rust after inoculation with two Puccinia melanocephala urediniospore concentrations

\begin{tabular}{|c|c|c|c|c|c|c|c|c|c|c|c|}
\hline \multicolumn{12}{|c|}{ Resistant seedlings from 11 crosses $(\%)^{\mathrm{z}}$} \\
\hline \multicolumn{2}{|c|}{$\mathbf{R} \times \mathbf{R}(\mathbf{1})$} & \multicolumn{2}{|c|}{$\mathbf{M S} \times \mathbf{R}(\mathbf{3})$} & \multicolumn{2}{|c|}{$\mathbf{R} \times \mathbf{H S}(\mathbf{1})$} & \multicolumn{2}{|c|}{$\mathbf{H S} \times \mathbf{R}(\mathbf{1})$} & \multicolumn{2}{|c|}{$\mathbf{M S} \times \mathbf{H S}(\mathbf{1})$} & \multicolumn{2}{|c|}{ HS $\times$ HS (4) } \\
\hline $1.0 \mathrm{E}+04$ & $1.0 \mathrm{E}+05$ & $1.0 \mathrm{E}+04$ & $1.0 \mathrm{E}+05$ & $1.0 \mathrm{E}+04$ & $1.0 \mathrm{E}+05$ & $1.0 \mathrm{E}+04$ & $1.0 \mathrm{E}+05$ & $1.0 \mathrm{E}+04$ & $1.0 \mathrm{E}+05$ & $1.0 \mathrm{E}+04$ & $1.0 \mathrm{E}+05$ \\
\hline 100 & 83 & 7 & 3 & 77 & 58 & 83 & 17 & 60 & 19 & 100 & 10 \\
\hline$\ldots$ & $\ldots$ & 100 & 100 & $\ldots$ & $\ldots$ & $\ldots$ & $\ldots$ & $\ldots$ & $\ldots$ & 99 & 84 \\
\hline$\ldots$ & $\ldots$ & 100 & 93 & $\ldots$ & $\ldots$ & $\ldots$ & $\ldots$ & $\ldots$ & $\ldots$ & 97 & 33 \\
\hline$\ldots$ & $\ldots$ & $\ldots$ & $\ldots$ & $\ldots$ & $\ldots$ & $\ldots$ & $\ldots$ & $\ldots$ & $\ldots$ & 100 & 58 \\
\hline
\end{tabular}

${ }^{\mathrm{z}}$ Crosses were made between parents rated as resistant (R), moderately susceptible (MS), or highly susceptible (HS) to brown rust. Parent ratings were based on repeated field observations of natural infection severity. The numbers of crosses of each type are shown after the cross type in parentheses. Seedlings were inoculated with two urediniospore concentrations: $1 \times 10^{4}(1.0 \mathrm{E}+04)$ and $1 \times 10^{5}(1.0 \mathrm{E}+05)$ spores $/ \mathrm{ml}$. Values are percentages of seedlings rated as resistant from 11 different crosses determined after inoculation with $P$. melanocephala urediniospores.

Table 4. Brown rust severity and resistance ratings based on severity for sugarcane clones in three controlled-conditions inoculations

\begin{tabular}{|c|c|c|c|c|c|c|c|c|c|}
\hline \multirow[b]{3}{*}{ Clone $^{y}$} & \multicolumn{6}{|c|}{ Inoculation $^{w}$} & \multirow{2}{*}{\multicolumn{2}{|c|}{ Average $^{\mathrm{x}}$}} & \multirow{3}{*}{$\underset{\text { Rating }^{\mathbf{z}}}{\text { Qualitative }}$} \\
\hline & \multicolumn{2}{|c|}{ First } & \multicolumn{2}{|c|}{ Second } & \multicolumn{2}{|c|}{ Third } & & & \\
\hline & Infection (\%) & Rating & Infection (\%) & Rating & Infection (\%) & Rating & Infection (\%) & Rating & \\
\hline LCP 85-384 (HS) & $1.1 \mathrm{~b}$ & 8 & $1.3 \mathrm{c}$ & 2 & $3.5 \mathrm{a}$ & 9 & 2.0 & 6 & MS \\
\hline НоСР 85-845 & $0.7 \mathrm{~b}$ & 5 & $1.3 \mathrm{c}$ & 2 & $3.4 \mathrm{a}$ & 9 & 1.8 & 5 & MS \\
\hline LCP 86-454 & $4.1 \mathrm{~b}$ & 9 & $0.8 \mathrm{c}$ & 1 & $0.9 \mathrm{bcd}$ & 3 & 1.9 & 4 & MS \\
\hline НоСР 91-552 & $0.2 \mathrm{~b}$ & 2 & $1.1 \mathrm{c}$ & 2 & $0.7 \mathrm{~cd}$ & 2 & 0.7 & 2 & $\mathrm{R}$ \\
\hline НоСР 92-624 & $0.3 \mathrm{~b}$ & 2 & $0.5 \mathrm{c}$ & 1 & $1.8 \mathrm{abcd}$ & 6 & 0.8 & 3 & $\mathrm{R}$ \\
\hline НоСР 92-648 & $0.2 \mathrm{~b}$ & 1 & $11.8 \mathrm{a}$ & 9 & $1.9 \mathrm{abcd}$ & 6 & 4.6 & 5 & MS \\
\hline Ho 95-988 (HS) & $0.6 \mathrm{~b}$ & 4 & $15.1 \mathrm{ab}$ & 9 & $0.8 \mathrm{~cd}$ & 3 & 5.5 & 5 & MS \\
\hline НоCP 96-540 (HS) & $1.5 \mathrm{~b}$ & 9 & $0.7 \mathrm{c}$ & 1 & $3.0 \mathrm{abc}$ & 9 & 1.7 & 6 & MS \\
\hline L 99-226 (HS) & $0.3 \mathrm{~b}$ & 2 & $4.2 \mathrm{bc}$ & 6 & $1.9 \mathrm{abcd}$ & 6 & 2.1 & 5 & MS \\
\hline L 99-233 (R) & $0.3 \mathrm{~b}$ & 2 & $0.7 \mathrm{c}$ & 1 & $0.0 \mathrm{~d}$ & 1 & 0.3 & 1 & $\mathrm{R}$ \\
\hline L $01-283$ & $0.8 \mathrm{~b}$ & 6 & $0.2 \mathrm{c}$ & 1 & $0.5 \mathrm{~cd}$ & 2 & 0.5 & 3 & $\mathrm{R}$ \\
\hline L 01-299 (R) & $0.1 \mathrm{~b}$ & 1 & $0.2 \mathrm{c}$ & 1 & $0.1 \mathrm{~d}$ & 1 & 0.1 & 1 & $\mathrm{R}$ \\
\hline L 03-371 & $0.6 \mathrm{~b}$ & 4 & $0.5 \mathrm{c}$ & 1 & $2.1 \mathrm{abcd}$ & 6 & 1.1 & 4 & MS \\
\hline НоСР 04-838 & $0.3 \mathrm{~b}$ & 3 & $3.8 \mathrm{bc}$ & 4 & $0.7 \mathrm{~cd}$ & 2 & 1.6 & 3 & $\mathrm{R}$ \\
\hline НоСР 04-847 & $1.0 \mathrm{~b}$ & 7 & $2.5 \mathrm{c}$ & 4 & $3.3 \mathrm{ab}$ & 9 & 2.3 & 7 & HS \\
\hline L 06-038 & $0.3 \mathrm{~b}$ & 2 & $1.2 \mathrm{c}$ & 2 & $0.9 \mathrm{~cd}$ & 3 & 0.8 & 2 & $\mathrm{R}$ \\
\hline Но 06-563 & $0.1 \mathrm{~b}$ & 1 & $2.5 \mathrm{c}$ & 4 & $0.8 \mathrm{~cd}$ & 3 & 1.2 & 4 & MS \\
\hline Но 07-613 & $0.9 \mathrm{~b}$ & 7 & $1.2 \mathrm{c}$ & 2 & $2.0 \mathrm{abcd}$ & 6 & 1.4 & 5 & MS \\
\hline L 08-092 & $0.5 \mathrm{~b}$ & 4 & $3.7 \mathrm{c}$ & 4 & $1.3 \mathrm{abcd}$ & 4 & 1.8 & 4 & MS \\
\hline L 09-113 & $0.1 \mathrm{~b}$ & 1 & $0.2 \mathrm{c}$ & 1 & $0.3 \mathrm{~d}$ & 1 & 0.2 & 1 & $\mathrm{R}$ \\
\hline L 09-114 & $12.2 \mathrm{a}$ & 9 & $0.9 \mathrm{c}$ & 2 & $0.8 \mathrm{~cd}$ & 3 & 4.6 & 5 & MS \\
\hline Average & 1.2 & 4 & 2.6 & 3 & 1.5 & 4 & 1.8 & 4 & $\ldots$ \\
\hline
\end{tabular}

${ }^{\mathrm{w}}$ For three inoculations, disease severity was assessed as the percentage of leaf area occupied by brown rust lesions (\% infection). Infection percentages within a column followed by the same letter were not significantly different according to Tukey's test at $P=0.05$. Ratings for resistance were assigned on a 1 -to- 9 scale in which ratings of 1 to 3 were resistant, 4 to 6 were moderately susceptible, and 7 to 9 were highly susceptible.

$\mathrm{x}$ Average clone severities and resistance ratings based on three inoculations.

y Six cultivars with known brown rust resistance reactions (shown in parentheses) were included, with HS $=$ highly susceptible and R $=$ resistant.

${ }^{\mathrm{z}}$ Qualitative resistance ratings were assigned from the numerical ratings with resistant (R) assigned for ratings of 1 to 3, moderately susceptible (MS) for ratings of 4 to 6 , and highly susceptible for ratings of 7-9. 
Clone inoculations. An overall analysis determined that the clone $(F=1.22, P=0.2526)$, inoculation $(F=2.88, P=0.0599)$, and replication (plant) $(F=1.67, P=0.1930)$ effects were not significant. The clone-inoculation interaction was significant $(F=1.54, P=$ $0.035)$. Therefore, the individual experiment results were compared to determine where the variability occurred that resulted in the lack of ability to distinguish clones with different levels of resistance and whether useful information could be obtained with controlledconditions inoculations.

Leaf area occupied by lesions was 0.1 to $12.2 \%$ in inoculation one, 0.2 to $15.1 \%$ in inoculation two, and 0.1 to $3.5 \%$ in inoculation three, and differences were detected among clones within the inoculations (Table 4). Disease severity varied among clones between inoculations, particularly for those exhibiting susceptibility. Resistant L 99-233 exhibited severities of $0.2,0.6$, and $0.1 \%$, and resistant $\mathrm{L}$ 01-299 exhibited severities of $0.1,0.2$, and $0.1 \%$ in the first, second, and third inoculations, respectively, whereas susceptible LCP 85384, Ho 95-988, HoCP 96-540, and L 99-226 exhibited variable severities of $1.1,1.3$, and 3.5; 0.6, 15.1, and 0.8; 1.5, 0.7, and 3.0; and $0.3,4.2$, and 1.9 , respectively (Table 4 ). Severity ratings illustrated the variability for cultivars between the three inoculations, particularly for the $\mathrm{S}$ cultivars (Table 4 ). Ratings for cultivars known to be $S$ were 8,2 , and 9; 4, 9, and 3; 9, 1, and 9; and 2, 6, and 6 for LCP 85-384, Ho 95-988, HoCP 96-540, and L 99-226, respectively. In contrast, ratings for the two R cultivars were 2 , 1 , and 1 for L 99233 and 1 for all three experiments for L 01-299.

Resistance ratings in field nurseries. All of the 28 clones in the field nurseries exhibited some level of brown rust infection (Table 5). Severity ratings ranged from 3 to 8 for the first two nurseries and

Table 5. Brown rust resistance ratings from three field nurseries for 28 sugarcane clones based on natural infection severity

\begin{tabular}{|c|c|c|c|}
\hline \multirow[b]{2}{*}{ Clone $^{\mathrm{z}}$} & \multicolumn{3}{|c|}{$\begin{array}{c}\text { Severity ratings from three field } \\
\text { nurseries }^{y}\end{array}$} \\
\hline & First & Second & Third \\
\hline TucCP 77-042 & 6 & 3 & 4 \\
\hline LCP 81-010 & 7 & 4 & 6 \\
\hline LCP 85-384 (HS) & 8 & 8 & 7 \\
\hline НоСР 85-845 & 3 & 3 & 4 \\
\hline LCP 86-454 & 4 & 4 & 4 \\
\hline НоСР 91-552 & 5 & 3 & 4 \\
\hline НоСР 92-624 & 8 & NI & 7 \\
\hline НоСР 92-648 & 5 & 6 & 5 \\
\hline L 94-432 & 4 & 4 & 5 \\
\hline Ho 95- 988 (HS) & 8 & 8 & 7 \\
\hline НоСР 96-540 (HS) & 6 & 4 & 6 \\
\hline L 97-128 & 6 & 4 & 4 \\
\hline L 98-207 & 8 & 8 & 8 \\
\hline L 98-209 & 6 & 4 & 7 \\
\hline L 99-226 (HS) & 4 & 4 & 6 \\
\hline L 99-233 (R) & 3 & NI & 2 \\
\hline US 01-040 & 4 & 3 & 4 \\
\hline L 01-299 (R) & 4 & NI & 2 \\
\hline НоСР 02-618 & 4 & 4 & 5 \\
\hline L 03-371 & 4 & NI & 3 \\
\hline НоCP $04-838$ & 4 & NI & 5 \\
\hline НоСР 04-847 & 5 & NI & 2 \\
\hline L 06-001 & 4 & 4 & 4 \\
\hline Ho $06-563$ & 6 & NI & 6 \\
\hline L 07-057 & 4 & 4 & 6 \\
\hline L 07-068 & 4 & 4 & 4 \\
\hline Но 07-613 & 5 & NI & 6 \\
\hline L 08-090 & 6 & 4 & 6 \\
\hline
\end{tabular}

${ }^{y}$ Resistance ratings were assigned on a 1-to-9 scale, in which ratings of 1 to 3 were resistant, 4 to 6 were moderately susceptible, and 7 to 9 were highly susceptible. $\mathrm{NI}=$ not included in the nursery.

z Six commercial cultivars with known brown rust resistance reactions (shown in parentheses) were included, with HS = highly susceptible and $\mathrm{R}=$ resistant. from 2 to 8 in the third. Ratings for the $\mathrm{S}$ cultivars were 8,8 , and 7 for LCP 85-384; 8, 8, and 7 for Ho 95-988; 6, 4, and 6 for HoCP 96-540; and 4, 4, and 6 for L 99-226 in the first, second, and third nurseries, respectively. The two $\mathrm{R}$ cultivars were only included in two nurseries. L 99-233 and L 01-299 had ratings of 3 and 2 and ratings of 4 and 2 in the first and third nurseries, respectively. The Shapiro-Wilk test found a lack of normality in the severity ratings (Shapiro-Wilk $=0.96, P<0.0001$ ). Spearman's rank correlations for the 20 clones common to all three nurseries indicated that only the severity ratings from the first and third field nurseries were correlated $(\rho=0.4710$ and $P=0.0311$ ). Comparing the first and second nurseries, $\rho=-0.1692$ and $P=0.4633$; and, comparing the second and third nurseries, $\rho=0.2366$ and $P=0.3016$.

Brown rust severity rating comparisons between controlledconditions inoculations and field nurseries with natural infection. Severity ratings from controlled-conditions inoculations were compared with field natural infection severity ratings for 16 clones (Table 6). The severity ratings showed low Spearman's rank correlations between the rankings from the three controlled-conditions inoculations and two field nurseries with natural infection (Table 7). Ratings from the first and third controlled-conditions inoculations were nearly significantly correlated $(\rho=0.49, P=0.055)$. The ratings from the first and third field nurseries from natural infection were correlated $(\rho=$ $0.64, P=0.007$ ). The average and high severity ratings of clones in controlled-conditions inoculations and natural field infection were tested for correlation. Clone average and high severity ratings were highly correlated for comparisons within either controlled-conditions inoculations or field nurseries (Table 8). In comparisons of average and high ratings between controlled-conditions inoculation and natural field infection, correlations ranged from to $0.41(P=0.11)$ to $0.25(P=$ $0.34)$ between high ratings for controlled-conditions inoculation and average ratings for natural field infection and between high ratings for controlled-conditions inoculation and natural field infection, respectively.

\section{Discussion}

The concentration of $P$. melanocephala urediniospores affected the severity of infection of sugarcane seedlings following inoculation under controlled conditions. This, in turn, affected the frequency of $\mathrm{R}$ progeny recorded in biparental crosses. The results demonstrate that, when seedlings are inoculated with a high inoculum concentration

Table 6. Brown rust resistance ratings from three controlled-conditions inoculations and two field nurseries with natural infection for 16 sugarcane clones ${ }^{y}$

\begin{tabular}{|c|c|c|c|c|c|}
\hline \multirow[b]{2}{*}{ Clone $^{\mathrm{z}}$} & \multicolumn{3}{|c|}{ Controlled conditions } & \multicolumn{2}{|c|}{$\begin{array}{l}\text { Natural } \\
\text { infection }\end{array}$} \\
\hline & First & Second & Third & First & Third \\
\hline LCP 85-384 (HS) & 8 & 2 & 9 & 8 & 7 \\
\hline НоСР 85-845 & 5 & 2 & 9 & 3 & 4 \\
\hline LCP 86-454 & 9 & 1 & 3 & 4 & 4 \\
\hline HoCP 91-552 & 2 & 2 & 2 & 5 & 4 \\
\hline НоСР 92-624 & 2 & 1 & 6 & 8 & 7 \\
\hline НоСР 92-648 & 1 & 9 & 6 & 5 & 5 \\
\hline Ho 95-988 (HS) & 4 & 9 & 3 & 8 & 7 \\
\hline НоСР 96-540 (HS) & 9 & 1 & 9 & 6 & 6 \\
\hline L 99-226 (HS) & 2 & 6 & 6 & 4 & 6 \\
\hline L 99-233 (R) & 2 & 1 & 1 & 3 & 2 \\
\hline L $01-283$ & 6 & 1 & 2 & 8 & 4 \\
\hline L 01-299 (R) & 1 & 1 & 1 & 4 & 2 \\
\hline HoCP 04-838 & 3 & 4 & 2 & 4 & 5 \\
\hline НоСР 04-847 & 7 & 4 & 9 & 5 & 2 \\
\hline Ho 06-563 & 1 & 9 & 3 & 6 & 6 \\
\hline Но 07-613 & 7 & 2 & 6 & 5 & 5 \\
\hline
\end{tabular}

${ }^{\mathrm{y}}$ Ratings for clones in three inoculations or two field nurseries were assigned on a 1-to- 9 scale, in which ratings of 1 to 3 were resistant, 4 to 6 were moderately susceptible, and 7 to 9 were highly susceptible.

${ }^{z}$ Six commercial cultivars with known brown rust resistance reactions (shown in parentheses) were included, with HS = highly susceptible and $\mathrm{R}=$ resistant 
under highly favorable conditions for infection, brown rust resistance can be ineffective.

The mechanisms of resistance to brown rust are still being elucidated. A major brown rust resistance gene, Bru1, with dominant effect was reported (Daugrois et al. 1996). Bru1 has been shown to prevent infection by diverse rust isolates collected from widespread geographic origins and, thus far, has provided a high level of durable resistance (Asnaghi et al. 2001). Bru1 is widely distributed, with variable frequency in the breeding population and cultivars in different areas (Costet et al. 2012; Glynn et al. 2010). This gene occurs at low frequency in Louisiana sugarcane germplasm (Parco et al. 2014). It is present in only one commercial cultivar, L 01-299. This cultivar was a parent in one of the crosses in this study, XL 11-256 $(\mathrm{MS} \times \mathrm{R})$, and there was a high frequency of R seedlings $(95 \%)$ following inoculation with $1 \times 10^{5}$ spores $/ \mathrm{ml}$. Unfortunately, this cross was not inoculated with the highest inoculum concentration to evaluate how $\mathrm{R}$ phenotype frequency would be affected by high inoculum pressure in the presence of Bru1 in the seedling population.

A second R cultivar, L 99-233, included in three crosses in the study, was previously demonstrated to exhibit quantitative resistance to brown rust (Hoy et al. 2014). Seedlings in two crosses with L 99233 as a parent, XL 09-003 (MS $\times$ R) and XL 09-100 (HS $\times$ R), showed a strong effect of inoculum concentration on the frequency of a R phenotype, while all of the seedlings in XL 11-144 (MS $\times$ $\mathrm{R})$ were rated as $\mathrm{R}$ even at the higher spore concentration of $1 \times$ $10^{5}$ spores $/ \mathrm{ml}$.

The frequency distribution of seedlings across ratings was affected by inoculum concentration regardless of the resistance reactions of the parents being crossed. Inoculation with the lowest $\left(1 \times 10^{3}\right.$ spores $/ \mathrm{ml})$ and highest $\left(1 \times 10^{6}\right.$ spores $\left./ \mathrm{ml}\right)$ inoculum concentrations resulted in seedling frequency distributions that were skewed toward $\mathrm{R}$ or $\mathrm{S}$ ratings, respectively. Inoculation with $1 \times 10^{6} \mathrm{spores} / \mathrm{ml}$ overwhelmed resistance. Inoculation with $1 \times 10^{4}$ and $1 \times 10^{5}$ spores $/ \mathrm{ml}$ resulted in a wider distribution of ratings for some crosses. However, an optimal combination of inoculum concentration for comparing crosses was not obvious. Disease severity was lower in the second inoculation, possibly due to a shorter (2- to 3-h) leaf wetness period, but urediniospore germination was lower also in the second inoculation. An increase in disease severity with increasing leaf wetness period was demonstrated previously for brown rust (Barrera et al. 2012); however, leaf wetness periods between 10 and $13 \mathrm{~h}$ were favorable for infection.

Resistance to brown rust has been shown repeatedly to be a heritable trait in sugarcane (Comstock et al. 1992; González et al. 1987; Hogarth et al. 1993; Tai et al. 1981). Therefore, a higher frequency of $\mathrm{R}$ progeny would be expected to occur in crosses involving $\mathrm{R}$ parents. The inoculation of seedling populations from biparental crosses under controlled conditions did not consistently produce this expected outcome. Comparing infection severity ratings for the progeny of 11 crosses, parental reaction was not a consistent determinant of the frequency of $\mathrm{R}$ offspring.

Because parental reaction was not a consistent determinant of progeny distribution across resistance categories, seedling inoculation under controlled conditions to evaluate brown rust resistance will not be useful as a part of cross appraisal in the sugarcane breeding program. Resistance mechanisms to brown rust are either not fully expressed or can be overwhelmed in seedlings under conditions highly favorable for disease. The results suggest that the use of seedlings to identify resistance to brown rust in a cultivar selection program should be approached with caution.

In this study, a single inoculation under controlled conditions with $P$. melanocephala urediniospores could not consistently detect differences among a group of clones with variable levels of resistance to brown rust. This outcome suggested that the technique may not be useful for resistance screening. However, an evaluation of the individual experiment results for the cultivars with known resistance reactions revealed that $\mathrm{S}$ clones exhibited variability in severity levels, whereas infection severities across inoculations were consistently low for $\mathrm{R}$ clones. These results suggest that accurate determination of clone resistance reactions can be obtained by multiple inoculations. Variable quantitative responses to inoculation in the field occur with two other sugarcane pathogens, Sporisorium scitaminea and Xanthomonas albilineans, the causal agents of smut and leaf scald, respectively (J. W. Hoy, unpublished). Information needed to characterize unreleased clone resistance levels to these diseases is obtained by conducting multiple annual inoculations, including cultivars with known resistance reaction, and considering average and high clone ratings across experiments in making selection decisions.

Like most traits in sugarcane, resistance to brown rust is quantitatively inherited and expressed (Comstock et al. 1992; D'Hont et al. 1996; González et al. 1987; Hogarth et al. 1993; Tai et al. 1981). Field resistance reactions to brown rust are known to be variable for $\mathrm{S}$ clones and are determined by repeated observations of natural infection severity over multiple seasons. Inoculation of young, clonally propagated plants and symptom development under controlled conditions was evaluated to attempt to develop a method that would avoid the effects of variable environmental conditions and inoculum exposure on phenotypic expression of resistance. However, despite efforts to create uniform conditions favorable for infection and disease development (Barrera et al. 2012), erratic results were obtained for $\mathrm{S}$ clones in different experiments. Infection severities were lower than those observed in the field. Additional evaluation of the inoculum and environmental variables in the system may lead to more realistic and repeatable infection and symptom development.

Table 8. Spearman's rank correlations for average and high brown rust severity ratings from controlled-conditions inoculations $(\mathrm{CCI})$ and field nurseries with natural infection $(\mathrm{NI})^{\mathrm{z}}$

\begin{tabular}{|c|c|c|c|c|c|c|c|c|}
\hline \multirow[b]{2}{*}{ Experiment } & \multicolumn{2}{|c|}{ Average CCI } & \multicolumn{2}{|c|}{ Average NI } & \multicolumn{2}{|c|}{ High CCI } & \multicolumn{2}{|c|}{$\begin{array}{c}\text { High } \\
\text { NI } \\
\end{array}$} \\
\hline & $\rho$ & $P$ & $\rho$ & $P$ & $\rho$ & $P$ & $\rho$ & $P$ \\
\hline Average CCI & 1 & & & & . & . & & \\
\hline Average NI & 0.393 & 0.132 & 1 & $\ldots$ & & $\ldots$ & $\ldots$ & \\
\hline High CCI & 0.815 & 0.0001 & 0.414 & 0.110 & 1 & $\ldots$ & $\ldots$ & \\
\hline High NI & 0.325 & 0.2192 & 0.946 & 0.0001 & 0.254 & 0.340 & 1 & \\
\hline
\end{tabular}

${ }^{z} \rho$ Spearman's rank correlation coefficient.

Table 7. Spearman's rank correlations for brown rust resistance ratings from three controlled-conditions inoculations (CCI) and two field nurseries with natural infection $(\mathrm{NI})^{\mathrm{z}}$

\begin{tabular}{|c|c|c|c|c|c|c|c|c|c|c|}
\hline \multirow[b]{3}{*}{ Experiment } & \multicolumn{6}{|c|}{ Controlled-conditions inoculation } & \multicolumn{4}{|c|}{ Natural infection } \\
\hline & \multicolumn{2}{|c|}{ First } & \multicolumn{2}{|c|}{ Second } & \multicolumn{2}{|c|}{ Third } & \multicolumn{2}{|c|}{ First } & \multicolumn{2}{|c|}{ Third } \\
\hline & $\rho$ & $P$ & $\rho$ & $P$ & $\rho$ & $P$ & $\rho$ & $P$ & $\boldsymbol{\rho}$ & $P$ \\
\hline First CCI & 1 & $\ldots$ & $\ldots$ & $\ldots$ & $\ldots$ & $\ldots$ & $\ldots$ & $\ldots$ & $\ldots$ & $\ldots$ \\
\hline Second CCI & 0.322 & 0.223 & 1 & $\ldots$ & $\ldots$ & $\ldots$ & $\ldots$ & $\ldots$ & $\ldots$ & $\ldots$ \\
\hline Third CCI & 0.488 & 0.055 & 0.209 & 0.43 & 1 & $\ldots$ & $\ldots$ & $\ldots$ & $\ldots$ & $\ldots$ \\
\hline First NI & 0.173 & 0.519 & 0.089 & 0.742 & 0.235 & 0.379 & 1 & $\ldots$ & $\ldots$ & $\ldots$ \\
\hline Third NI & 0.06 & 0.814 & 0.345 & 0.189 & 0.399 & 0.125 & 0.64 & 0.007 & 1 & $\ldots$ \\
\hline
\end{tabular}

${ }^{\mathrm{z}} \rho=$ Spearman's rank correlation coefficient. 
Controlled-conditions inoculation and natural field infection results were not highly correlated in this study. Average and high ratings from multiple inoculations were moderately but not significantly correlated with natural field infection. Differential reactions between cultivars and pathogen populations from different cultivars have been demonstrated in Louisiana (Hoy et al. 2014). The controlledconditions inoculations in this study were done with urediniospore populations collected from one cultivar, Ho 95-988. The inoculum for natural infection of clones in the field nurseries would have come predominately from HoCP 96-540, a cultivar that exhibited differential reactions in comparison with Ho 95-988 (Hoy et al. 2014). This difference could have affected the severity ratings of clones between controlled-conditions inoculation and natural field infection, and pathogenic variability within the pathogen population is a factor that must be considered in future research evaluating resistance.

Brown rust has become an important disease of sugarcane in Louisiana. Disease resistance has been overcome in 10 of the last 13 cultivars released from the breeding program (J. W. Hoy, unpublished). Accurate characterization of resistance is needed for potential parents. However, methodology commonly used with rusts in other crops is not available for sugarcane, and severity ratings based on natural infection have been problematic. Multiple inoculations of plants under controlled conditions accurately identified $\mathrm{R}$ and $\mathrm{S}$ clones, with severe infection resulting from any single inoculation indicating susceptibility. Therefore, controlled-conditions inoculation has the potential to be useful in studies to characterize parents in a recurrent selection program and for basic studies of resistance to brown rust.

\section{Acknowledgments}

We thank C. F. Savario for expert technical assistance and the American Sugar Cane League for financial support.

\section{Literature Cited}

Anderson, D. L., and Dean, J. L. 1986. Relationship of rust severity and plant nutrients in sugarcane. Phytopathology 76:581-585.

Anderson, D. L., Raid, R. N., Irey, M. S., and Henderson, L. J. 1990. Association of sugarcane rust severity with soil factors in Florida. Plant Dis. 74:683-686.

Asnaghi, C., D'Hont, A., Glaszmann, J., and Rott, P. 2001. Resistance of sugarcane cultivar R 570 to Puccinia melanocephala isolates from different geographic locations. Plant Dis. 85:282-286.

Avellaneda, M. C. 2014. Screening for resistance to sugarcane brown rust with controlled conditions inoculation. M.S. thesis, Louisiana State University Agricultural Center, Baton Rouge. Online publication. http://etd.lsu.edu/ docs/available/etd-07112014-170420/

Barrera, W., Hoy, J., and Li, B. 2012. Temperature and leaf wetness effects on infection of sugarcane by Puccinia melanocephala. J. Phytopathol. 160:294-298.

Barrera, W., Hoy, J., and Li, B. 2013. Effects of temperature and moisture variables on brown rust epidemics in sugarcane. J. Phytopathol. 161:98-106.

Comstock, J. C., and Ferreira, S. A. 1986. Sugarcane rust: Factors affecting infection and symptom development. Proc. Int. Soc. Sugar Cane Technol. 19:402-410.

Comstock, J. C., Wu, K. K., and Schnell, R. J. 1992. Heritability of resistance to sugar cane rust. Sugar Cane 6:7-10.

Costet, L., Le Cunff, L., Royaert, S., Raboin, L.-M., Hervouet, C., Toubi, L., Telismart, H., Garsmeur, O., Rousselle, Y., and Pauquet, J. 2012. Haplotype structure around Brul reveals a narrow genetic basis for brown rust resistance in modern sugarcane cultivars. Theor. Appl. Genet. 125:825-836.
Daugrois, J. H., Grivet, L., Roques, D., Hoarau, J. Y., Lombard, H., Glaszmann, J. C., and D'Hont, A. 1996. A putative major gene for rust resistance linked with a RFLP marker in sugarcane cultivar 'R570'. Theor. Appl. Genet. 92 $1059-1064$

Dean, J. L., and Purdy, L. H. 1984. Races of the sugar cane rust fungus, Puccinia melanocephala, found in Florida. Sugar Cane 1:15-16.

D’Hont, A., Grivet, L., Feldmann, P., Glaszmann, J., Rao, S., and Berding, N. 1996. Characterisation of the double genome structure of modern sugarcane cultivars (Saccharum spp.) by molecular cytogenetics. Mol. Gen. Genet. 250: 405-413.

Glynn, N. C., Dixon, L. J., Castlebury, L. A., Szabo, L. J., and Comstock, J. C. 2010. PCR assays for the sugarcane rust pathogens Puccinia kuehnii and $P$. melanocephala and detection of a SNP associated with geographical distribution in P. kuehnii. Plant Pathol. 59:703-711.

González, R. V., Manzano, C. A., Ordosgoitti, F. A., and Salazar, P. Y. 1987. Genetica de la reaccion de la caña de azucar (Saccharum spp.) a Puccinia melanocephala, causante de la roya. Agron. Trop. 37:99-116.

Hogarth, D. M., Ryan, C. C., and Taylor, P. W. J. 1993. Quantitative inheritance of rust resistance in sugarcane. Field Crops Res. 34:187-193.

Hoy, J. W., Avellaneda, M. C., and Bombecini, J. 2014. Variability in Puccinia melanocephala pathogenicity and resistance in sugarcane cultivars. Plant Dis. 98:1728-1732.

Hoy, J. W., and Hollier, C. A. 2009. Effect of brown rust on yield of sugarcane in Louisiana. Plant Dis. 93:1171-1174.

Hoy, J. W., and Savario, C. F. 2007. Can fungicides provide an alternative control measure for brown rust? J. Am. Soc. Sugar Cane Technol. 27:60.

Irey, M. 1987. Effect of the environment on sugarcane rust epidemics in Florida J. Am. Soc. Sugar Cane Technol. 7:30-35.

Johnson, R. M., Grisham, M. P., and Richard, E. P. 2007. Relationship between sugarcane rust severity and soil properties in Louisiana. Phytopathology 97: 748-755.

Parco, A. S., Avellaneda, M. C., Hale, A. H., Hoy, J. W., Kimbeng, C. A., Pontif, M. J., Gravois, K. A., and Baisakh, N. 2014. Frequency and distribution of the brown rust resistance gene Bru 1 and implications for the Louisiana sugarcane breeding programme. Plant Breed. 133:654-659.

Piperidis, G., D'Hont, A., and Hogarth, D. M. 2001. Chromosome composition analysis of various Saccharum interspecific hybrids by genomic in situ hybridization (GISH). Proc. Int. Soc. Sugar Cane Technol. 2: 565-566.

Purdy, L. H., Liu, L. J., and Dean, J. L. 1983. Sugarcane rust, a newly important disease. Plant Dis. 67:1292-1296.

Raid, R. N. 1989. Physiological specialization in sugarcane rust (Puccinia melanocephala) in Florida. Plant Dis. 73:183.

Raid, R. N., and Comstock, J. C. 2000. Common rust. Pages 85-89 in: A Guide to Sugarcane Diseases. P. Rott, R. A. Bailey, J. C. Comstock, B. J. Croft, and A. S. Saumtally, eds. CIRAD/ISSCT, Paris.

Sandoval, I., Picornell, V., Chaves, R., and Ramos, N. 1983. Puccinia melanocephala $\mathrm{H}$ \& P. Syd.: Biological and ecological aspects. Proc. Int. Soc. Sugar Cane Technol. 18:845-853.

Shine, J. M., Comstock, J. C., and Dean, J. L. 2005. Comparison of five isolates of sugarcane rust and differential reaction on six sugarcane clones. Proc. Int. Soc. Sugar Cane Technol. 25:638-647.

Sotomayor, I. A., Purdy, L. H., and Trese, A. T. 1983. Infection of sugarcane leaves by Puccinia melanocephala. Phytopathology 73:695-699.

Srinivasan, K. V., and Muthaiyan, M. C. 1965. A note on physiologic races in Puccinia erianthi Padw. and Khan affecting sugar-cane varieties. Proc. Int Soc. Sugar Cane Technol. 12:1126-1128.

Tai, P. Y. P., Miller, J. D., and Dean, J. L. 1981. Inheritance of resistance to rust in sugarcane. Field Crops Res. 4:261-268.

Victoria, J. I., Ochoa, B. O., and Gómez, J. F. 1984. La Roya de la caña en el valle del Cauca: diseminación y efecto en la producción. Pages 209-218 in: Memorias del I Congreso de la Sociedad Colombiana de Técnicos de la Caña de Azúcar, Tecnicaña. 